\title{
化学蚀变指数(CIA)反映长江流域的硅酸盐岩化学风化 与季风气候?
}

\author{
郡菁清，杨守业* \\ 同济大学海洋地质国家重点实验室, 长江水环境教育部重点实验室, 上海 200092 \\ * 联系人, E-mail: syyang@ tongji.edu.cn \\ 2011-08-03 收稿, 2011-12-09 接受 \\ 国家自然科学基金(41076018, 40830107)和长江水环境教育部重点实验室自主课题(YRWEY 1009)资助
}

\begin{abstract}
摘要 大陆化学风化显著影响全球气候变化、地表物质循环和海水化学组成, 如何定量地重建古 化学风化历史一直是全球变化研究的热点. 化学蚀变指数(CIA)被广泛用作衡量大陆硅酸盐岩化 学风化程度的定量指标, 其指示意义在前人研究中不断深化, 但对其具体计算方法和运用局限性 缺乏深入探讨. 研究长江千支流悬浮物的 CIA 值在时空上的变化特征, 揭示出 CIA 季节性的变化 反映长江流域季节性降雨区迁移导致下游干流悬浮物来源的不同, 由此提出 CIA 实际反映了流域 累积的综合化学风化历史, 而不是一个可靠的瞬时(季节性)化学风化指标, 不能指示短时间尺度 的季节性气候变化. 通过比较不同计算方法和沉积粒度对 CIA 的影响, 提出在 CIA 应用过程中应 该注意的关键问题.
\end{abstract}

\section{关键词}

化学风化

CIA

悬浮物

长江

气候
自 Raymo 等人 ${ }^{[1]}$ 提出“构造隆升-风化”假说以来, 新生代喜马拉雅-青藏高原隆升及其环境效应成为地 球系统科学和全球变化研究的重大科学问题. 青藏 高原隆升形成特色的亚洲季风和发育亚洲主要河流, 这些大河流域的化学风化控制表生地球化学过程, 对全球碳循环和海水化学组成具有重要影响 ${ }^{[2 \sim 7]}$. 如 何定量地评价大陆化学风化程度并重建古气候一直 是全球变化研究的热点, 不少学者提出了基于沉积 地球化学分析的各种化学风化指标 ${ }^{[8 \sim 16]}$. Nesbitt 和 Young ${ }^{[9]}$ 在研究加拿大古元古代的碎屑岩时, 首次提 出化学蚀变指数 (chemical index of alteration, CIA), 来计算长石类矿物风化成黏土矿物的程度, 作为反 映源区化学风化程度的指标. 过去 30 年来, CIA 被广 泛用来指示大陆流域硅酸盐岩化学风化程度, 其中 包括亚马逊流域 ${ }^{[17,18]}$ 、长江和黄河流域 ${ }^{[19,20]}$ 、南亚河 流(印度河、红河、湄公河、恒河) $)^{[2124]}$, 东南亚吕宋 岛河流 ${ }^{[25]}$, 台湾的河流 ${ }^{[26]}$, 及川西高原 ${ }^{[27]}$ 和华北平 原 ${ }^{[28]}$ 等区域. McLennan ${ }^{[29]}$ 汇总计算了世界上 16 条主
要河流悬浮物的 CIA 值, 提出悬浮物记录的化学风 化历史与主要流域侵蚀模数之间有很好相关性. 最 近, Li 和 Yang ${ }^{[20]}$ 更系统地研究了世界七大洲共 44 条 河流悬浮物的 CIA 组成, 探讨了 CIA 组成与流域面 积、年均温度、年均降雨量、径流量、土壤层厚度等 因素的关系, 提出了全球范围内 CIA 对年均温度, 土 壤层厚度和纬度等因素敏感, 而中国纬向分布的河 流流域受季风气候的影响, 其化学风化受温度、降雨 量、径流量控制; 他们的研究明显深化了 CIA 指标示 踪意义的认识. 但迄今, 对 CIA 具体计算方法、指示 意义和运用局限性仍然缺乏深人探讨, 如对单一 流域内河流沉积物中 CIA 组成的时空变化还未开展 系统研究, 对 CIA 是否可以指示流域内季节性的气 候变化也缺乏定论, 这显然制约了 CIA 指标的运用 前景.

长江是发源于青藏高原地区的第一大河, 其发 育历史直接记录了晚新生代构造隆升、亚洲季风气候 演化和东亚大陆风化特征, 因而过去百年来一直是

英文版见: Shao J Q, Yang S Y. Does chemical index of alteration (CIA) reflect silicate weathering and monsoonal climate in the Changjiang River basin? Chin Sci Bull, 2012, 57: 1178-1187, doi: 10.1007/s11434-011-4954-5 
科学界的研究热点. 长江沉积物作为流域各种源岩 风化产物的混合物, 可以反映流域风化上陆壳的平 均组成, 记录流域的风化历史 ${ }^{[19,30]}$. 本文首先研究长 江悬浮物 CIA 的空间变化规律, 探讨流域内硅酸盐 岩化学风化特征; 进而通过下游干流季节性悬浮物 CIA 的变化来探讨 CIA 组成与长江流域季风降雨的 关系; 此外, 比较 CIA 不同的计算方法对其值的影响, 提出 CIA 示踪应用中存在的一些问题.

\section{1 样品来源与分析方法}

\section{1 样品的采集}

长江干流、支流悬浮物样品分别采于 2001, 2004, 2008 和 2009 年的汛期, 采样点从上游金沙江到河口 均有分布(表 1). 其中, 从 2008 年 4 月到 2009 年 4 月, 还在南通附近的长江干流每周一次定期采集季 节性悬浮物样品. 悬浮物的采样位置为江中心的主 航道附近, 采用 $25 \mathrm{~L}$ 干净塑料桶采集表层以下近 $1 \mathrm{~m}$ 深处的江水, 在现场附近采用真空洜抽虑的方式用 $0.45 \mu \mathrm{m}$ 醋酸纤维滤膜过滤水样得到悬浮物, 在室内 $40^{\circ} \mathrm{C}$ 的烘箱中低温烘干, 研磨保存.

\section{2 沉积物化学分析和 CIA 计算方法}

为了讨论不同的计算方法对 CIA 值的影响, 本 文对南通 51 个季节性样品进行了酸洗预处理. 采用 浓度 $1 \mathrm{~mol} \mathrm{~L}^{-1}$ 的高纯盐酸淋洗样品, 得到酸不溶残 渣相, 并和长江其他悬浮物全样一起进行元素组成 测试. 元素分析时, 先将样品在马弗炉中 $600^{\circ} \mathrm{C}$ 下灼 烧 $2 \mathrm{~h}$, 去除有机质; 然后称取 $30 \mathrm{mg}$ 左右样品置于溶 样器中, 运用一定浓度的高纯 $\mathrm{HNO}_{3}$ 和 $\mathrm{HF}$ 消解样品. 在同济大学海洋地质国家重点实验室运用电感耦合 等离子体发射光谱仪(IRIS Advantage ICP-AES)测试 常量元素含量. GSD 系列标准样监测数据表明, 常量 元素的分析误差在 5\%以内.

CIA 的计算方法为: $\mathrm{Al}_{2} \mathrm{O}_{3} /\left(\mathrm{Al}_{2} \mathrm{O}_{3}+\mathrm{Na}_{2} \mathrm{O}+\mathrm{K}_{2} \mathrm{O}+\right.$ $\left.\mathrm{CaO}^{*}\right) \times 100$, 式中氧化物为摩尔质量百分比, 而 $\mathrm{CaO}^{*}$ 指的是硅酸盐矿物中的 $\mathrm{Ca}$ 含量, 不包括碳酸盐和磷 酸盐等矿物中结合的 $\mathrm{Ca}^{[9]}$. 显然, 由表生环境中元素 地球化学行为可知, CIA 实际反映了含铝硅酸盐矿物 尤其是长石风化成黏土矿物的程度 ${ }^{[9,12,31]}$. CIA 值越 高指示硅酸盐矿物中 $\mathrm{Na}, \mathrm{K}$ 和 $\mathrm{Ca}$ 矿物从母岩中淋失 越多, 化学风化越强 ${ }^{[32,33]}$. 由于实验过程中很难精确
地分离纯化沉积物样品中的硅酸盐矿物, 本文采用 $1 \mathrm{~mol} \mathrm{~L}^{-1}$ 浓度的高纯盐酸来去除非硅酸盐类的含 $\mathrm{Ca}$ 矿物, 将酸不溶相中的 $\mathrm{CaO}$ 含量用于 $\mathrm{CIA}$ 计算. 前人 研究揭示, $1 \mathrm{~mol} \mathrm{~L}^{-1}$ 盐酸可以有效地去除沉积物中的 碳酸盐、磷酸盐、部分自生 $\mathrm{Fe}-\mathrm{Mn}$ 氧化物矿物和少 量黏土矿物如绿泥石中吸附元素 ${ }^{[34,35]}$. 另外, 不少学 者在实际研究中并未采用酸溶方法来去除非硅酸盐 的含 $\mathrm{Ca}$ 矿物, 而是采用 McLennan ${ }^{[29]}$ 提出的校正方 法, 即根据自然界硅酸盐矿物中 $\mathrm{Na}$ 和 $\mathrm{Ca}$ 的平均组成, 依据沉积物样品中的 $\mathrm{CaO} / \mathrm{Na}_{2} \mathrm{O}$ 的摩尔比值来计算 CIA: 如果比值 $>1$, 以 $\mathrm{Na}_{2} \mathrm{O}$ 的摩尔含量代替 $\mathrm{CaO}$ 含 量; 而若比值 $<1$, 则直接以 $\mathrm{CaO}$ 摩尔含量来计算 CIA. 本文用该校正方法来计算长江流域悬浮物样品的 CIA 值, 而选择南通地区干流悬浮物样品, 比较两种 CIA 计算方法对结果的影响.

\section{2 长江悬浮物 CIA 的时空变化特征}

\section{1 长江流域悬浮物 CIA 值在空间上变化}

长江流域面积约 $180 \times 10^{4} \mathrm{~km}^{2}$, 由非常复杂的支 流水系组成. 自江源至湖北宜昌划属上游, 宜昌至江 西的湖口属中游, 湖口至长江口为下游. 长江主要支 流及干流悬浮物的 CIA 值见表 1 .

从长江上游到下游, 悬浮物中 CIA 在 65.8 77.6 间波动变化, 平均值为 72.1. 上游中峮江的 CIA 最低, 仅 65.8 ; 而泸州和宜宾处长江干流悬浮物的 CIA 最 高, 达 72.7. 中下游汉江的 CIA 比较低(69.1), 而南 京地区的干流 CIA 可达 77.6. 虽然从上游至下游 CIA 并非线性升高, 但上游悬浮物 CIA 平均值为 70.3(变 化范围为 $65.8 \sim 72.7)$, 中下游悬浮物 CIA 平均值为 74.1(变化范围为 69.1 77.6), 反映出明显的流域内区 域性变化规律(图 1).

长江干支流悬浮物 $\mathrm{CIA}$ 的平均值为 72.1 , 与 $\mathrm{Li}$ 和 $\mathrm{Yang}^{[20]}$ 的报道世界河流平均值一致, 而略高于 McLennan ${ }^{[29]}$ 的统计数据, 低于 Viers 等人 ${ }^{[37]}$ 统计的 平均值(表 1).

Yang 等人 ${ }^{[19]}$ 在讨论长江和黄河流域硅酸盐矿物 化学风化提出, 气候是控制化学风化的主要因素, 源 岩等其他因素影响不大. Li 和 Yang 比较研究了全球 主要河流的 CIA 组成, 认为相比全球流域而言, 我国 纬向分布的主要河流流域的硅酸盐岩化学风化对气 候的响应比源岩、流域面积和物理侵蚀模数更为敏感; 
表 1 长江干、支流悬浮物主要氧化物含量及 CIA 值

\begin{tabular}{|c|c|c|c|c|c|c|c|}
\hline 样品点 & 经纬度 & 采样日期 & $\mathrm{K}_{2} \mathrm{O}(\mathrm{wt} \%)$ & $\mathrm{Na}_{2} \mathrm{O}(\mathrm{wt} \%)$ & $\mathrm{CaO}(\mathrm{wt} \%)$ & $\mathrm{Al}_{2} \mathrm{O}_{3}(\mathrm{wt} \%)$ & CIA \\
\hline 石鼓 & $26^{\circ} 53^{\prime} 25^{\prime \prime} \mathrm{N}, 99^{\circ} 57^{\prime} 46^{\prime \prime} \mathrm{E}$ & 2004-08-07 & 1.71 & 0.65 & 3.86 & 8.81 & 68.7 \\
\hline 攀枝花 & $26^{\circ} 36^{\prime} 45^{\prime \prime} \mathrm{N}, 101^{\circ} 48^{\prime} 01^{\prime \prime} \mathrm{E}$ & 2004-08-08 & 1.98 & 0.65 & 3.97 & 11.23 & 72.4 \\
\hline 乐山 1 & $29^{\circ} 33^{\prime} 11^{\prime \prime} \mathrm{N}, 103^{\circ} 45^{\prime} 54^{\prime \prime} \mathrm{E}$ & 2004-08-10 & 2.50 & 0.78 & 3.75 & 11.91 & 69.3 \\
\hline 乐山 2 & $29^{\circ} 33^{\prime} 22^{\prime \prime} \mathrm{N}, 103^{\circ} 46^{\prime} 05^{\prime \prime} \mathrm{E}$ & 2004-08-11 & 2.07 & 0.72 & 3.98 & 8.89 & 65.8 \\
\hline 宜宾 & $28^{\circ} 46^{\prime} 07^{\prime \prime} \mathrm{N}, 104^{\circ} 37^{\prime} 45^{\prime \prime} \mathrm{E}$ & 2004-08-11 & 1.79 & 0.57 & 3.94 & 10.14 & 72.7 \\
\hline 泸州 & $28^{\circ} 54^{\prime} 07^{\prime \prime} \mathrm{N}, 105^{\circ} 26^{\prime} 58^{\prime \prime} \mathrm{E}$ & 2004-08-12 & 2.36 & 0.72 & 4.11 & 13.08 & 72.7 \\
\hline 重庆 & $29^{\circ} 33^{\prime} 52^{\prime \prime} \mathrm{N}, 106^{\circ} 35^{\prime} 08^{\prime \prime} \mathrm{E}$ & 2004-08-13 & 1.99 & 0.72 & 3.98 & 9.87 & 68.5 \\
\hline 万州 & $30^{\circ} 48^{\prime} 44^{\prime \prime} \mathrm{N}, 108^{\circ} 23^{\prime} 01^{\prime \prime} \mathrm{E}$ & 2004-08-14 & 2.50 & 0.73 & 3.77 & 13.13 & 72.0 \\
\hline 仙桃 & $30^{\circ} 22^{\prime} 47^{\prime \prime} \mathrm{N}, 113^{\circ} 26^{\prime} 48^{\prime \prime} \mathrm{E}$ & 2004-08-16 & 2.56 & 1.12 & 2.29 & 14.45 & 69.1 \\
\hline 南京 $1^{a)}$ & $32^{\circ} 05^{\prime} 34^{\prime \prime} \mathrm{N}, 118^{\circ} 43^{\prime} 28^{\prime \prime} \mathrm{E}$ & 2006-10 2007-09 & 2.95 & 0.64 & 2.60 & 18.56 & 77.6 \\
\hline 南京 2 & $32^{\circ} 08^{\prime} 24^{\prime \prime} \mathrm{N}, 118^{\circ} 46^{\prime} 24^{\prime \prime} \mathrm{E}$ & 2001-08-24 & 3.45 & 0.71 & 3.99 & 19.74 & 76.4 \\
\hline 镇江 1 & $32^{\circ} 15^{\prime} 23^{\prime \prime} \mathrm{N}, 119^{\circ} 26^{\prime} 09^{\prime \prime} \mathrm{E}$ & 2001-08-26 & 3.14 & 0.71 & 4.35 & 17.40 & 75.3 \\
\hline 镇江 2 & $32^{\circ} 15^{\prime} 01^{\prime \prime} \mathrm{N}, 119^{\circ} 24^{\prime} 59^{\prime \prime} \mathrm{E}$ & $2001-08-26$ & 3.21 & 0.70 & 4.37 & 17.64 & 75.3 \\
\hline 南通 & $31^{\circ} 57^{\prime} 24^{\prime \prime} \mathrm{N}, 120^{\circ} 51^{\prime} 53^{\prime \prime} \mathrm{E}$ & 2008-04-03 & 2.79 & 1.43 & 2.36 & 19.28 & 71.4 \\
\hline 南通 & $31^{\circ} 57^{\prime} 24^{\prime \prime} \mathrm{N}, 120^{\circ} 51^{\prime} 53^{\prime \prime} \mathrm{E}$ & 2008-04-10 & 2.89 & 0.99 & 2.57 & 18.97 & 74.8 \\
\hline 南通 & $31^{\circ} 57^{\prime} 24^{\prime \prime} \mathrm{N}, 120^{\circ} 51^{\prime} 53^{\prime \prime} \mathrm{E}$ & 2008-04-18 & 3.05 & 0.77 & 1.31 & 20.74 & 78.0 \\
\hline 南通 & $31^{\circ} 57^{\prime} 24^{\prime \prime} \mathrm{N}, 120^{\circ} 51^{\prime} 53^{\prime \prime} \mathrm{E}$ & 2008-04-24 & 2.94 & 0.97 & 2.13 & 18.76 & 74.6 \\
\hline 南通 & $31^{\circ} 57^{\prime} 24^{\prime \prime} \mathrm{N}, 120^{\circ} 51^{\prime} 53^{\prime \prime} \mathrm{E}$ & 2008-04-29 & 2.67 & 0.95 & 2.42 & 17.33 & 74.2 \\
\hline 南通 & $31^{\circ} 57^{\prime} 24^{\prime \prime} \mathrm{N}, 120^{\circ} 51^{\prime} 53^{\prime \prime} \mathrm{E}$ & 2008-05-09 & 2.62 & 0.91 & 2.80 & 20.42 & 77.8 \\
\hline 南通 & $31^{\circ} 57^{\prime} 24^{\prime \prime} \mathrm{N}, 120^{\circ} 51^{\prime} 53^{\prime \prime} \mathrm{E}$ & $2008-05-15$ & 2.15 & 1.10 & 1.89 & 24.26 & 80.3 \\
\hline 南通 & $31^{\circ} 57^{\prime} 24^{\prime \prime} \mathrm{N}, 120^{\circ} 51^{\prime} 53^{\prime \prime} \mathrm{E}$ & $2008-05-21$ & 2.68 & 1.49 & 2.25 & 24.53 & 75.8 \\
\hline 南通 & $31^{\circ} 57^{\prime} 24^{\prime \prime} \mathrm{N}, 120^{\circ} 51^{\prime} 53^{\prime \prime} \mathrm{E}$ & $2008-05-27$ & 2.67 & 0.95 & 2.93 & 17.51 & 74.4 \\
\hline 南通 & $31^{\circ} 57^{\prime} 24^{\prime \prime} \mathrm{N}, 120^{\circ} 51^{\prime} 53^{\prime \prime} \mathrm{E}$ & 2008-06-06 & 2.01 & 1.04 & 4.19 & 12.93 & 69.8 \\
\hline 南通 & $31^{\circ} 57^{\prime} 24^{\prime \prime} \mathrm{N}, 120^{\circ} 51^{\prime} 53^{\prime \prime} \mathrm{E}$ & $2008-06-15$ & 2.96 & 0.86 & 2.81 & 20.31 & 77.1 \\
\hline 南通 & $31^{\circ} 57^{\prime} 24^{\prime \prime} \mathrm{N}, 120^{\circ} 51^{\prime} 53^{\prime \prime} \mathrm{E}$ & $2008-06-20$ & 2.68 & 1.25 & 3.84 & 17.21 & 71.0 \\
\hline 南通 & $31^{\circ} 57^{\prime} 24^{\prime \prime} \mathrm{N}, 120^{\circ} 51^{\prime} 53^{\prime \prime} \mathrm{E}$ & 2008-06-27 & 2.87 & 0.84 & 1.77 & 20.23 & 77.5 \\
\hline 南通 & $31^{\circ} 57^{\prime} 24^{\prime \prime} \mathrm{N}, 120^{\circ} 51^{\prime} 53^{\prime \prime} \mathrm{E}$ & 2008-07-04 & 3.02 & 0.90 & 2.18 & 19.88 & 76.1 \\
\hline 南通 & $31^{\circ} 57^{\prime} 24^{\prime \prime} \mathrm{N}, 120^{\circ} 51^{\prime} 53^{\prime \prime} \mathrm{E}$ & 2008-07-11 & 3.05 & 0.93 & 1.84 & 21.03 & 76.7 \\
\hline 南通 & $31^{\circ} 57^{\prime} 24^{\prime \prime} \mathrm{N}, 120^{\circ} 51^{\prime} 53^{\prime \prime} \mathrm{E}$ & 2008-07-18 & 2.63 & 0.99 & 3.64 & 18.18 & 74.8 \\
\hline 南通 & $31^{\circ} 57^{\prime} 24^{\prime \prime} \mathrm{N}, 120^{\circ} 51^{\prime} 53^{\prime \prime} \mathrm{E}$ & $2008-07-24$ & 2.97 & 1.17 & 4.19 & 19.06 & 72.9 \\
\hline 南通 & $31^{\circ} 57^{\prime} 24^{\prime \prime} \mathrm{N}, 120^{\circ} 51^{\prime} 53^{\prime \prime} \mathrm{E}$ & 2008-08-02 & 2.68 & 0.98 & 3.83 & 16.82 & 73.2 \\
\hline 南通 & $31^{\circ} 57^{\prime} 24^{\prime \prime} \mathrm{N}, 120^{\circ} 51^{\prime} 53^{\prime \prime} \mathrm{E}$ & 2008-08-08 & 2.82 & 1.16 & 4.36 & 16.82 & 71.0 \\
\hline 南通 & $31^{\circ} 57^{\prime} 24^{\prime \prime} \mathrm{N}, 120^{\circ} 51^{\prime} 53^{\prime \prime} \mathrm{E}$ & $2008-08-14$ & 3.01 & 1.00 & 3.60 & 18.14 & 73.4 \\
\hline 南通 & $31^{\circ} 57^{\prime} 24^{\prime \prime} \mathrm{N}, 120^{\circ} 51^{\prime} 53^{\prime \prime} \mathrm{E}$ & $2008-08-22$ & 2.72 & 1.01 & 4.65 & 15.82 & 71.6 \\
\hline 南通 & $31^{\circ} 57^{\prime} 24^{\prime \prime} \mathrm{N}, 120^{\circ} 51^{\prime} 53^{\prime \prime} \mathrm{E}$ & 2008-08-29 & 2.65 & 0.89 & 5.67 & 15.58 & 72.8 \\
\hline 南通 & $31^{\circ} 57^{\prime} 24^{\prime \prime} \mathrm{N}, 120^{\circ} 51^{\prime} 53^{\prime \prime} \mathrm{E}$ & 2008-09-06 & 3.15 & 1.06 & 6.03 & 17.62 & 71.8 \\
\hline 南通 & $31^{\circ} 57^{\prime} 24^{\prime \prime} \mathrm{N}, 120^{\circ} 51^{\prime} 53^{\prime \prime} \mathrm{E}$ & 2008-09-11 & 3.01 & 1.03 & 4.27 & 18.16 & 73.2 \\
\hline 南通 & $31^{\circ} 57^{\prime} 24^{\prime \prime} \mathrm{N}, 120^{\circ} 51^{\prime} 53^{\prime \prime} \mathrm{E}$ & 2008-09-19 & 2.60 & 1.18 & 5.79 & 14.99 & 69.1 \\
\hline 南通 & $31^{\circ} 57^{\prime} 24^{\prime \prime} \mathrm{N}, 120^{\circ} 51^{\prime} 53^{\prime \prime} \mathrm{E}$ & $2008-09-26$ & 2.81 & 1.10 & 5.71 & 16.41 & 71.1 \\
\hline 南通 & $31^{\circ} 57^{\prime} 24^{\prime \prime} \mathrm{N}, 120^{\circ} 51^{\prime} 53^{\prime \prime} \mathrm{E}$ & 2008-10-04 & 2.78 & 1.16 & 6.33 & 16.57 & 70.8 \\
\hline 南通 & $31^{\circ} 57^{\prime} 24^{\prime \prime} \mathrm{N}, 120^{\circ} 51^{\prime} 53^{\prime \prime} \mathrm{E}$ & 2008-10-11 & 3.03 & 0.90 & 4.74 & 17.97 & 74.2 \\
\hline 南通 & $31^{\circ} 57^{\prime} 24^{\prime \prime} \mathrm{N}, 120^{\circ} 51^{\prime} 53^{\prime \prime} \mathrm{E}$ & $2008-10-18$ & 2.67 & 1.21 & 4.77 & 15.88 & 69.8 \\
\hline 南通 & $31^{\circ} 57^{\prime} 24^{\prime \prime} \mathrm{N}, 120^{\circ} 51^{\prime} 53^{\prime \prime} \mathrm{E}$ & $2008-10-25$ & 2.84 & 0.97 & 4.19 & 17.97 & 74.1 \\
\hline 南通 & $31^{\circ} 57^{\prime} 24^{\prime \prime} \mathrm{N}, 120^{\circ} 51^{\prime} 53^{\prime \prime} \mathrm{E}$ & 2008-11-01 & 2.92 & 1.01 & 4.48 & 17.75 & 73.2 \\
\hline 南通 & $31^{\circ} 57^{\prime} 24^{\prime \prime} \mathrm{N}, 120^{\circ} 51^{\prime} 53^{\prime \prime} \mathrm{E}$ & 2008-11-08 & 3.06 & 0.84 & 2.29 & 21.50 & 77.9 \\
\hline 南通 & $31^{\circ} 57^{\prime} 24^{\prime \prime} \mathrm{N}, 120^{\circ} 51^{\prime} 53^{\prime \prime} \mathrm{E}$ & $2008-11-15$ & 2.75 & 1.08 & 4.23 & 16.98 & 72.2 \\
\hline 南通 & $31^{\circ} 57^{\prime} 24^{\prime \prime} \mathrm{N}, 120^{\circ} 51^{\prime} 53^{\prime \prime} \mathrm{E}$ & $2008-11-22$ & 2.95 & 0.73 & 3.13 & 18.61 & 76.9 \\
\hline 南通 & $31^{\circ} 57^{\prime} 24^{\prime \prime} \mathrm{N}, 120^{\circ} 51^{\prime} 53^{\prime \prime} \mathrm{E}$ & 2008-11-29 & 2.84 & 0.93 & 4.64 & 17.89 & 74.4 \\
\hline
\end{tabular}


(续表 1)

\begin{tabular}{|c|c|c|c|c|c|c|c|}
\hline 样品点 & 经纬度 & 采样日期 & $\mathrm{K}_{2} \mathrm{O}(\mathrm{wt} \%)$ & $\mathrm{Na}_{2} \mathrm{O}(\mathrm{wt} \%)$ & $\mathrm{CaO}(\mathrm{wt} \%)$ & $\mathrm{Al}_{2} \mathrm{O}_{3}(\mathrm{wt} \%)$ & CIA \\
\hline 南通 & $31^{\circ} 57^{\prime} 24^{\prime \prime} \mathrm{N}, 120^{\circ} 51^{\prime} 53^{\prime \prime} \mathrm{E}$ & $2008-12-06$ & 2.82 & 0.85 & 3.16 & 19.40 & 76.8 \\
\hline 南通 & $31^{\circ} 57^{\prime} 24^{\prime \prime} \mathrm{N}, 120^{\circ} 51^{\prime} 53^{\prime \prime} \mathrm{E}$ & $2008-12-14$ & 2.67 & 1.01 & 3.74 & 17.16 & 73.3 \\
\hline 南通 & $31^{\circ} 57^{\prime} 24^{\prime \prime} \mathrm{N}, 120^{\circ} 51^{\prime} 53^{\prime \prime} \mathrm{E}$ & $2008-12-20$ & 2.95 & 0.96 & 3.01 & 20.12 & 76.0 \\
\hline 南通 & $31^{\circ} 57^{\prime} 24^{\prime \prime} \mathrm{N}, 120^{\circ} 51^{\prime} 53^{\prime \prime} \mathrm{E}$ & $2008-12-27$ & 2.88 & 0.91 & 3.80 & 18.91 & 75.5 \\
\hline 南通 & $31^{\circ} 57^{\prime} 24^{\prime \prime} \mathrm{N}, 120^{\circ} 51^{\prime} 53^{\prime \prime} \mathrm{E}$ & 2009-01-03 & 2.98 & 0.98 & 3.40 & 19.44 & 75.0 \\
\hline 南通 & $31^{\circ} 57^{\prime} 24^{\prime \prime} \mathrm{N}, 120^{\circ} 51^{\prime} 53^{\prime \prime} \mathrm{E}$ & 2009-01-08 & 2.85 & 1.21 & 3.26 & 18.35 & 72.2 \\
\hline 南通 & $31^{\circ} 57^{\prime} 24^{\prime \prime} \mathrm{N}, 120^{\circ} 51^{\prime} 53^{\prime \prime} \mathrm{E}$ & 2009-01-15 & 2.71 & 1.01 & 4.00 & 16.80 & 72.9 \\
\hline 南通 & $31^{\circ} 57^{\prime} 24^{\prime \prime} \mathrm{N}, 120^{\circ} 51^{\prime} 53^{\prime \prime} \mathrm{E}$ & 2009-01-20 & 2.83 & 0.94 & 3.60 & 18.38 & 74.9 \\
\hline 南通 & $31^{\circ} 57^{\prime} 24^{\prime \prime} \mathrm{N}, 120^{\circ} 51^{\prime} 53^{\prime \prime} \mathrm{E}$ & 2009-02-04 & 2.83 & 1.11 & 3.38 & 17.99 & 72.8 \\
\hline 南通 & $31^{\circ} 57^{\prime} 24^{\prime \prime} \mathrm{N}, 120^{\circ} 51^{\prime} 53^{\prime \prime} \mathrm{E}$ & 2009-02-10 & 2.74 & 1.20 & 4.20 & 17.11 & 71.1 \\
\hline 南通 & $31^{\circ} 57^{\prime} 24^{\prime \prime} \mathrm{N}, 120^{\circ} 51^{\prime} 53^{\prime \prime} \mathrm{E}$ & 2009-02-18 & 2.87 & 1.28 & 2.41 & 19.32 & 72.5 \\
\hline 南通 & $31^{\circ} 57^{\prime} 24^{\prime \prime} \mathrm{N}, 120^{\circ} 51^{\prime} 53^{\prime \prime} \mathrm{E}$ & 2009-02-18 & 2.62 & 1.26 & 3.32 & 16.53 & 70.3 \\
\hline 南通 & $31^{\circ} 57^{\prime} 24^{\prime \prime} \mathrm{N}, 120^{\circ} 51^{\prime} 53^{\prime \prime} \mathrm{E}$ & 2009-03-08 & 2.61 & 0.97 & 2.53 & 18.42 & 75.4 \\
\hline 南通 & $31^{\circ} 57^{\prime} 24^{\prime \prime} \mathrm{N}, 120^{\circ} 51^{\prime} 53^{\prime \prime} \mathrm{E}$ & 2009-03-15 & 2.45 & 1.15 & 3.49 & 15.54 & 70.7 \\
\hline 南通 & $31^{\circ} 57^{\prime} 24^{\prime \prime} \mathrm{N}, 120^{\circ} 51^{\prime} 53^{\prime \prime} \mathrm{E}$ & 2009-03-22 & 2.70 & 0.87 & 1.88 & 18.51 & 76.1 \\
\hline 南通 & $31^{\circ} 57^{\prime} 24^{\prime \prime} \mathrm{N}, 120^{\circ} 51^{\prime} 53^{\prime \prime} \mathrm{E}$ & 2009-04-03 & 2.65 & 1.01 & 1.60 & 19.33 & 75.8 \\
\hline 长兴岛 & $31^{\circ} 29^{\prime} 37^{\prime \prime} \mathrm{N}, 121^{\circ} 31^{\prime} 16^{\prime \prime} \mathrm{E}$ & 2001-08-28 & 3.20 & 0.96 & 3.79 & 16.48 & 71.3 \\
\hline \multicolumn{2}{|c|}{ 南通样品平均值(51) } & & & 1.03 & 3.50 & 18.30 & $73.9(75.8)$ \\
\hline \multicolumn{2}{|c|}{ 长江悬浮物平均值(65) } & & & 0.97 & 3.56 & 17.32 & 72.1 \\
\hline \multicolumn{2}{|c|}{ 世界河流平均值(16) ${ }^{\mathrm{b})}$} & & & 1.33 & 3.84 & 17.98 & 71.6 \\
\hline \multicolumn{2}{|c|}{ 世界河流平均值 $(60)^{\mathrm{c})}$} & & & 0.96 & 3.63 & 16.47 & 75.5 \\
\hline \multicolumn{2}{|c|}{ 世界河流平均值 $(44)^{\mathrm{d})}$} & & & 1.21 & 3.57 & 16.40 & 72.1 \\
\hline
\end{tabular}

a) 来自文献[36]; b) 来自文献[29]; c) 来自文献[37]; d) 来自文献[20]; 世界河流平均值后的括号数据表示统计河流数; 南通样品平 均值后括号中的 CIA 值计算方法是依据酸不溶相中的 $\mathrm{CaO}$ 含量，而其他 CIA 值则依据 McLennan ${ }^{[29}$ 提出的校正方法

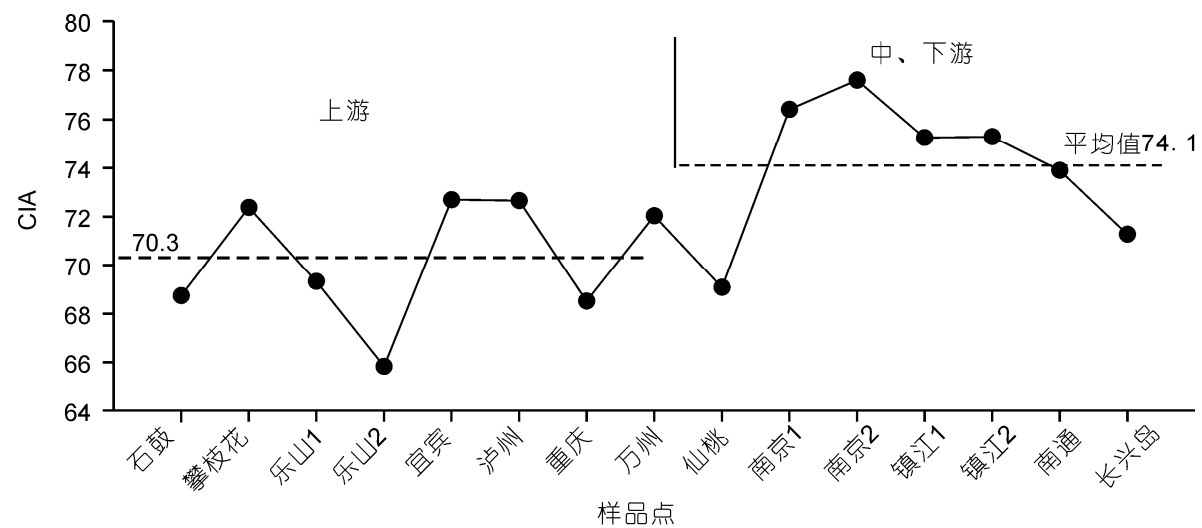

图 1 长江干、支流悬浮物中 CIA 的空间变化

我国河流沉积物的 CIA 变化与流域温度、降雨量和 径流深均有很好的相关性 ${ }^{[20]}$.

多年平均输沙量数据揭示, 长江中下游悬浮物 主要来源于上游广大地区 ${ }^{[38,39]}$, 但中下游悬浮物的 CIA 普遍高于上游干、支流悬浮物(图 1). CIA 主要反

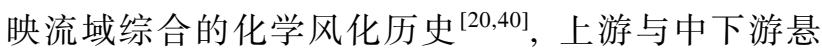
浮物不同的 CIA 组成反映来源于中下游流域的细颗
粒侵蚀物经历了更强的化学风化，硅酸盐矿物蚀变 成黏土的程度相对上游更显著. 整个长江流域主要 受亚洲季风气候的控制 ${ }^{[41]}$, 流域大部分坐落在温带 至亚热带的季风气候区内, 但上游和中、下游地区的 平均温度, 降雨量有很大的差别. 上游年平均温度为 $5 \sim 15^{\circ} \mathrm{C}$, 平均降雨量为 $150 \sim 1000 \mathrm{~mm}$, 而中、下游地 区平均温度为 $16 \sim 18^{\circ} \mathrm{C}$, 降雨量为 $1200 \mathrm{~mm}^{[42,43]}$, 明 
显高于上游流域. 在流域源岩组成上, 上游的峨眉山 玄武岩是我国最大的玄武岩省, 青藏高原源区的新 生代岩浆岩分布较广, 而中下游印支期和燕山期花 岗岩分布多, 古老变质岩也出露多, 因此长江宽广流 域内基岩组成相当复杂，从基性到酸性均有分布，且 从上游到中下游并没有主导性的源岩类型.

长江支流水系相当复杂, 尤其是上游地区集中 了长江最大的几条支流(金沙江、雅聋江、岷江、大 渡河、嘉陵江、乌江、沱江等), 河流细颗粒悬浮物 可以基本反映流域内不同源岩风化物质的混合，代 表各自流域风化上陆壳的平均组成 ${ }^{[19]}$. 在长江流域 不同地区, 季风气候差异(气温、降雨、径流深及相 应的植被发育)是制约源岩化学风化的主要因素, 中 下游地区的气候条件更有利于化学风化的进行. 而 从构造角度看, 长江的青藏高原源区及上游地区受 新构造运动影响显著, 新生代抬升剥蚀快, 新鲜岩石 暴露多而有利于化学风化进行, 但由于上游源区气 候条件恶劣且快速剥蚀使得土壤层并不发育, 硅酸 盐岩风化难以深人进行. 而中下游的扬子克拉通相 对稳定，地形坡降小，适宜的气候条件使得化学风化 更为完全. 另外, 长江中下游由于河道拓宽和河床坡 降变缓, 河漫滩发育, 河漫滩的化学风化可明显改变 河流沉积物的组成 ${ }^{[44 \sim 6]}$, 这可能也是中下游悬浮物 CIA 高于上游的原因, 但河漫滩化学风化的具体贡 献值得今后深人研究.

长江悬浮物主要以黏土矿物(约 $30 \%$ 60\%)和石 英 $(20 \%$ 左右)为主, 含少量长石及碳酸盐类矿物. 不 同地区黏土矿物组合类似，但上游绿泥石相对较多， 而下游高岭石含量稍高 ${ }^{[47]}$; 而且伊利石化学指数和 结晶指数从上游向中下游逐渐增大, 均反映出长江 中下游地区硅酸盐矿物风化成黏土矿物的程度要明 显强于上游流域 ${ }^{[36]}$. 值得注意的是, 长江上游地区 地形坡度大, 河水流速快, 水动力相比中下游强, 导 致上游悬浮物的平均粒径明显大于中下游干流 ${ }^{[47]}$, 而黏土矿物主要富集在细颗粒中, 因此水动力分选 也会一定程度上影响悬浮物的 CIA 计算, 这将在下 文具体论证. 个别河流例如岷江黏土矿物含量较其 他河段要低 ${ }^{[47]}$, 可能是其 CIA 值较低的原因.

\section{2 长江流域悬浮物 CIA 值的季节性变化}

南京和南通均位于长江下游干流, 其干流悬浮 物可以反映长江人海悬浮物的基本组成. 为了探讨
季节性悬浮物中 CIA 的变化特征, 我们比较了南京和 南通地区的两组数据. 南京干流悬浮物样品来自 $\mathrm{Mao}$ 等人 ${ }^{[36]}$, 采集于 2006 年 10 月至 2007 年 9 月, 每月采 样 1 2 次; 南通样品由本研究采集于 2008 年 4 月至 2009 年 4 月, 每周采样 1 次, 具体数据见表 1 和图 2 .

虽然两组样品采自不同地点和不同年份的洪季 和枯季, 悬浮物 CIA 的具体数据也不同, 但它们的季 节性变化趋势很相似(图 2). 洪季(5 10 月)悬浮物 CIA 都呈现先降低后上升的趋势，在 8 和 9 月平均值 最低; 枯季(11月至次年 4 月)悬浮物 CIA 虽然也波动 变化, 但较洪季波动范围小, CIA 值也多高于洪季样 品. 其中, 南通地区洪季悬浮物 CIA 平均为 73.6, 枯 季为 74.2 ; 而南京附近洪季悬浮物 CIA 平均为 76.1, 枯季为 78.9.

洪季长江人海悬浮物的 CIA 低于枯季, 似乎有 悖于前文提出的气候是控制长江悬浮物 CIA 组成的 主要因素, 因为在洪季流域气温与降水都要显著高 于枯季, 硅酸盐岩化学风化理应更强, 因此 CIA 值应 该高于枯季. 这提醒我们需要重新考虑 CIA 这个指 标的示踪意义. 长江下游干流悬浮物的 CIA 实际反 映了流域内进入下游干流的不同来源悬浮物的平均 组成, 显然季节性悬浮物 CIA 组成差异也反映了下 游悬浮颗粒物质来源的变化. 长江流域受亚洲季风 影响显著, 不仅仅流域内年均降雨量分布不平均, 且 在不同时间降雨区也在迁移. 3 6 月, 长江流域降雨 区主要分布在中下游地区，7 月雨区逐渐西移至四川 盆地，中下游地区梅雨期结束并开始伏旱时期，8 9 月雨带中心继续往上游迁移, 10 月开始至次年 3 月降 雨变少且雨区又逐渐往中下游迁移 ${ }^{[48]}$. 强烈的降雨 和地表径流直接控制表土的物理剥蚀过程, 将大量 的风化产物和新鲜碎屑矿物带入河流. 流域季节性 的降雨区迁移使得进人下游干流的悬浮物来源(上游 和中下游的相对贡献)也明显发生变化. 而长江中下 游悬浮物的 CIA 值普遍高于上游地区(图 1), 从而影 响长江人海悬浮物 CIA 的季节性变化. 洪季 5 6月, 强降雨带位于中下游地区，中下游流域物理风化加 强, 对下游干流的悬浮细颗粒物质贡献增多, 导致 5 6 月人海悬浮物的 CIA 值较高(图 2); 7 9 月强降雨 区向上游地区迁移，上游强烈的物理剥蚀输运大量 碎屑物质进人下游干流，使得这期间人海悬浮物中 来自上游的组分占主导, CIA 值较低; 从 10 月开始降 雨带又逐渐往中下游迁移, 另外三峡水库的枯季蓄 

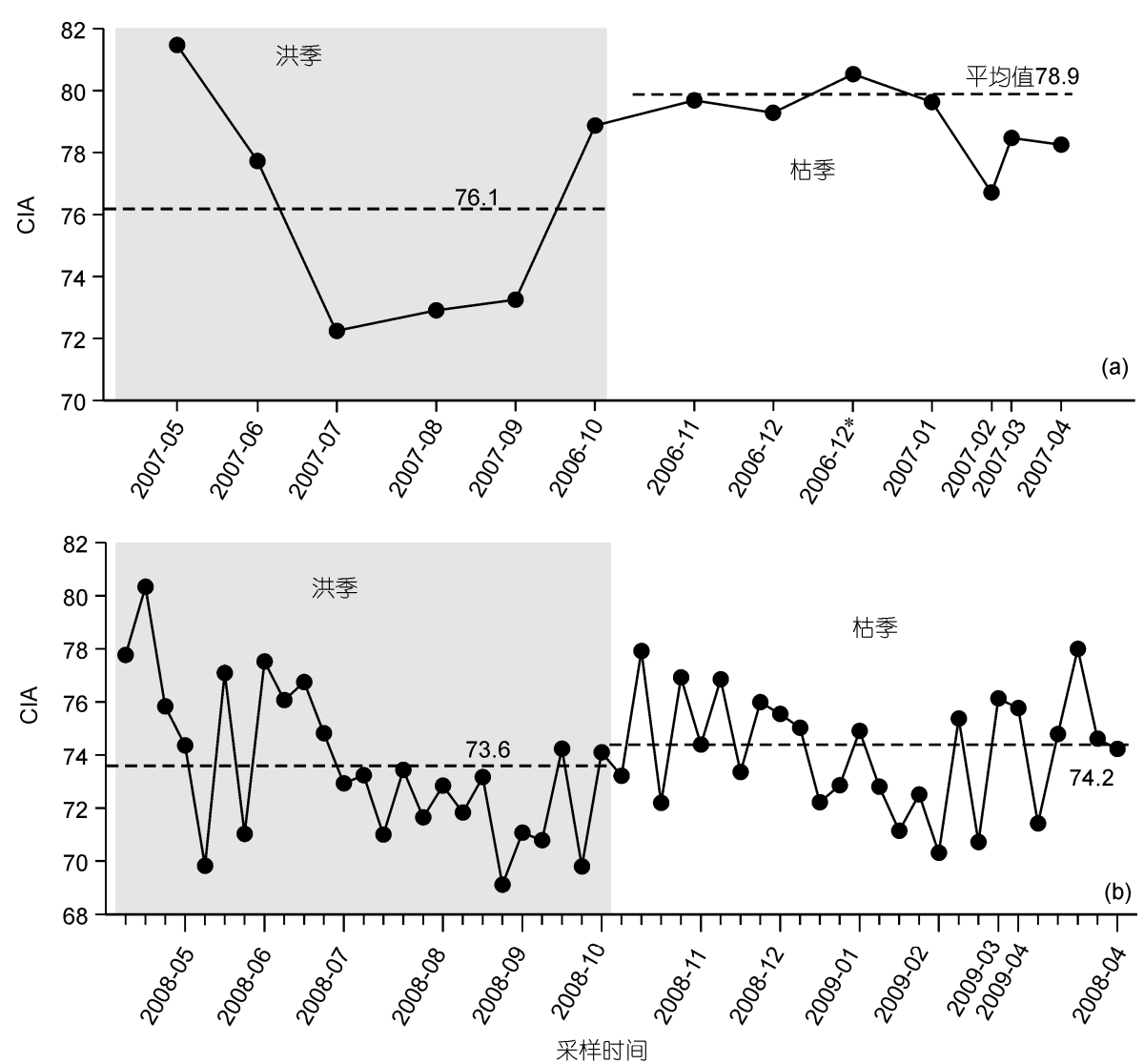

图 2 长江流域悬浮物 CIA 值季节性变化

(a) 南京样品 ${ }^{[36]}$; (b) 南通样品(本文研究). * 表示 2006 年 12 月第 21 次采样

水也拦截了大量上游侵蚀来沙 ${ }^{[49 \sim 51]}$, 使得中下游流 域的物质输人对河口区的悬浮物贡献比例又逐渐增 大，使得 CIA 值总体又逐渐升高.

枯季不同月份悬浮物的 CIA 也存在一些波动, 可能与中下游一些河流物质贡献有关, 如汉江虽然 在中游汇人长江, 但其产沙主要位于流域上游的黄 土堆积区, CIA 较低(表 1, 图 1). 从上述讨论来看, 本文研究也再次证实河流沉积物 CIA 主要反映流域 内较长时间尺度的综合化学风化历史, 与沉积物的 旋回性密切相关，而不能反映短时间尺度的“瞬时化 学风化”和季节性气候变化. 因此, 运用 CIA 指标来 指示硅酸盐化学风化和气候演化时, 一定要注意研 究的时间尺度.

\section{CIA 计算与研究应用的局限性}

\section{1 不同的计算方法对 CIA 值的影响}

自 1982 年 Nesbitt 和 Young ${ }^{[9]}$ 首次提出 CIA 以来,
该指标得到了广泛的运用, 因公式中 $\mathrm{CaO} *$ 代表硅酸 盐矿物中 $\mathrm{CaO}$ 含量, 需要采用化学处理去除非硅酸 盐组分; 为估算沉积物中 $\mathrm{CaO}$ *组成, McLennan ${ }^{[29]}$ 提 出一个比较 $\mathrm{Na}_{2} \mathrm{O}$ 与 $\mathrm{CaO}$ 相对含量的校正方法, 也被 很多学者采用, 但两种估算 $\mathrm{CaO}$ *组成的不同方法对 CIA 计算结果的影响如何, 前人还没有深人考虑. 本 文选择南通干流一年悬浮物样品, 采用 $1 \mathrm{~mol} \mathrm{~L}^{-1}$ $\mathrm{HCl}$ 处理得到 $\mathrm{CaO}^{*}$, 并计算 $\mathrm{CIA}$; 同时, 也采用 McLennan ${ }^{[29]}$ 的校正方法来计算 CIA, 来比较两种计 算方法的异同. 显然, 两种计算方法得到的 CIA 存在 一定差异 (图 3). 采用 McLennan 校正方法所得的 CIA 值均低于酸处理方法所得 CIA, 两者差值 $(\Delta \mathrm{CIA})$ 多 在 1 3 之间. 校正方法所得样品 CIA 的平均值为 73.9, 2 倍标准偏差为 5.1 , 变异系数为 3.5 ; 酸处理方法所 得 CIA 平均值为 $75.8,2$ 倍标准偏差为 4.8 , 变异系数 为 3.2. 两种计算方法得到的变异系数均大于 $\mathrm{Al}, \mathrm{K}$, $\mathrm{Na}$ 及 $\mathrm{Ca}$ 的分析精度 $(1.5 \%)$, 说明两种方法计算出的 CIA 差异主要不是由仪器分析精度所产生, 而可能 


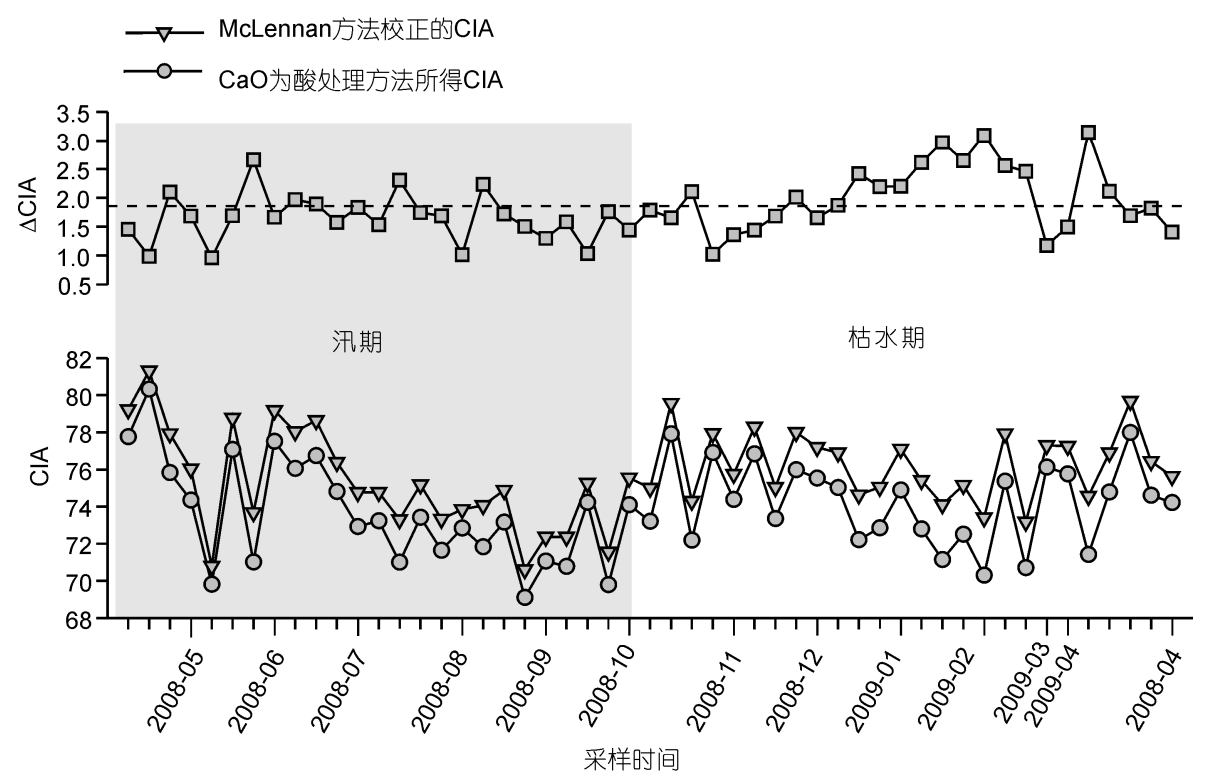

图 3 CIA 的不同计算方法对其结果影响

同样品性质和校正方法有关. 无论何种方法计算得 到的季节性悬浮物 CIA 组成的标准偏差均高于这两 种方法求得的 CIA 差值, 说明不同的计算方法对 CIA 结果并不会产生大的影响, 从它们的季节性变化曲 线非常类似也可以得到这认识. 但如果要精确比较 不同研究地区的 CIA 绝对大小, 在实际应用过程中 应该确保 CIA 计算方法的一致性.

\section{2 粒度对样品中 CIA 分析的影响}

沉积物中很多地球化学指标都受粒度控制, 那 么 CIA 是否也受粒度显著影响呢? 茅昌平 ${ }^{[47]}$ 讨论认 为长江上游沉积物的 CIA 值比悬浮物低, 说明水动 力分选作用使得悬浮物含较多的黏土组分, CIA 值高.

本文数据揭示, 无论是河漫滩沉积物还是悬浮 物, 粒度与 CIA 值都存在较好相关性; 而不同性质的 样品和流域不同地区的河流沉积物, 粒度与 CIA 的 相关性也不同(图 4(a), (b)), 且各相关系数在 0.01 水 平 (双侧)上进行相关性检验. 长江下游地区, 沉积物 (河漫滩沉积物和县浮物)CIA 值与平均粒径的相关性 很好, 相关系数达到 0.79 . 但粒度的影响在不同的粒 级不同, 对于较粗粒沉积物 $(\Phi<7.0)$ (图 4(a)), 平均粒 径与 CIA 值的相关性高 $\left(R^{2}=0.71\right)$; 而对于较细的悬 浮物 $(\Phi>7.0)$, 两者的相关性减弱 $\left(R^{2}=0.23\right)$. 而从整 个长江流域的河流悬浮物来看, 上游悬浮物粒度粗, CIA 值总体较低, 中下游悬浮物粒度相对细, CIA 值
高. 总体上, 整个长江悬浮物的平均粒径与 CIA 值的 相关性 $\left(R^{2}=0.49\right.$, 图 4(b)) 较下游的悬浮物要高 $\left(R^{2}=\right.$ 0.23 )(图 4(a)), 说明水动力分选可以影响长江河流悬 浮物 CIA 值在空间上的变化; 粒度越细, 黏土组分相 对富集, CIA 值就高. 但如果考虑到人海悬浮物(如本 文南通干流样品)的平均组成, 则 CIA 受悬浮物粒度 的影响非常弱, 这主要因为下游干流的悬浮颗粒物 是来自整个长江宽广流域内风化物质的混合, 且长 江下游干流河道拓宽, 河床坡度变小, 水动力较弱, 流速变缓, 导致悬浮物的平均粒径较细且变化不大.

因此, 在 CIA 的实际应用中需要考虑沉积粒度 的影响, 要注意到不同研究区域与样品性质对 CIA 的影响程度也不同. 总体上, 对于大河而言, 由于下 游干流或人海悬浮物作为整个流域上陆壳的细颗粒 风化物质的平均代表, 其 CIA 值主要反映了流域的 累积化学风化程度.

\section{4 主要结论}

通过长江流域不同地区河流沉积物化学蚀变指 数(CIA)组成的时空变化特征研究, 本文得出以下主 要结论:

(1) 长江主要干支流悬浮物的 CIA 介于 65.8 77.6 之间, 平均为 72.1, 与世界主要河流 CIA 平均值 比较接近. 总体上, 上游河流悬浮物的 CIA 值低于中 下游河流. CIA 作为反映流域累积化学风化程度的指 

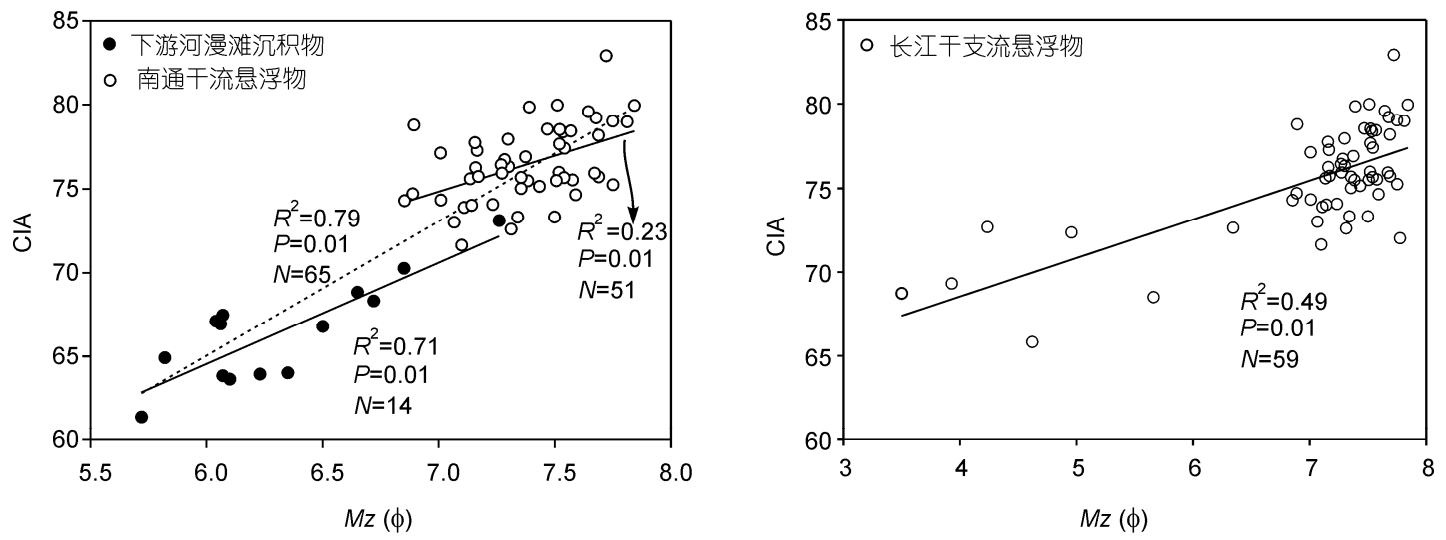

图 4 长江沉积物平均粒径 $(M z)$ 与 CIA 的相关图

(a) 长江下游河漫滩与悬浮沉积物 CIA 与粒度的相关性; 虚线代表总相关性; (b) 长江不同地区悬浮物 CIA 与粒度的相关性

标，长江不同地区悬浮物 CIA 的差异主要受流域的 季风气候控制.

(2) 南京和南通下游干流悬浮物的 CIA 存在明 显的季节性变化, 枯季悬浮物的 CIA 值多高于洪季. CIA 的季节性变化反映流域季节性降雨区迁移导致 下游干流悬浮物来源的不同(即上、中下游贡献差异). 这也进一步证明 CIA 不是一个瞬时(季节性)化学风 化指标.

(3) CIA 不同的计算方法对其结果有一定影响,
但对长江这样大河流不影响其长期时间变化序列的 研究. 而如果要精确比较不同研究地区的 CIA 绝对 大小，在实际应用过程中应该确保 CIA 计算方法的 一致性.

（4）河流悬浮物粒度对 CIA 的影响相对较弱, 且 下游干流悬浮物作为整个流域上陆壳的细颗粒风化 物质的平均代表, 其 CIA 值主要指示流域的累积化 学风化程度, 因此比较大陆硅酸盐化学风化时最好 选用代表性的悬浮物, 或者是相同粒级的沉积物.

\section{参考文献}

1 Raymo M E, Ruddiman W, Froelich P N. Influence of late Cenozoic mountain building on ocean geochemical cycles. Geology, 1988, 16: 649-653

2 Berner R A, Lasaga A C, Garrels R M. The carbonate-silicate geochemical cycle and its effect on atmospheric carbon dioxide over the past 100 million years. Am J Sci, 1983, 283: 641-683

3 Raymo M E, Ruddiman W F. Tectonic forcing of late Cenozoic climate. Nature, 1992, 359: 117-122

4 Krishnaswami S, Trivedi J R, Sarin M M, et al. Strontium isotopes and rubidium in the Ganges Brahmaputra river system weathering in the Himalaya, fluxes to the Bay of Bengal and contribution to the evolution of oceanic $\mathrm{Sr}^{87} / \mathrm{Sr}^{86}$. Earth Planet Sci Lett, 1992, 109: 243253

5 Suchet P A, Probst J L. Modeling of atmospheric $\mathrm{CO}_{2}$ consumption by chemical weathering of rocks: Application to the Garonne, Congo and Amazon basins. Chem Geol, 1993, 107: 205-210

6 Kump L R, Brantley S L, Arthur M A. Chemical weathering, atmospheric $\mathrm{CO}_{2}$, and climate. Annu Rev Earth Planet Sci, 2000, 28: 611667

7 Pierson-Wickmann A C, Reisberg L, France-Lanord C, et al. Os-Sr-Nd results from sediments in the Bay of Bengal: Implication for sediment transport and the marine Os record. Paleoceanography, 2001, 16: 435-444

8 Short N M. Geochemical variation in four residual soils. J Geol, 1961, 69: 534-571

9 Nesbitt H W, Young G M. Early Proterozoic climate and plate motion inferred from major element chemistry of lutites. Nature, 1982, 299: $715-717$

10 Harnois L. The CIW index: A new chemical index of weathering. Sediment Geol, 1988, 55: 319-322

11 Sueoka T. Identification and classification of granitic residual soils using chemical weathering index. In: Proceedings of the Second International Conference on Geomechanics in Tropical Soils, Singapore. 1988, 1: 55-61 
12 Fedo C M, Nesbitt H W, Young G M. Unraveling the effects of potassium metasomatism in sedimentary rocks and paleosols, with implications for paleo-weathering conditions and provenance. Geology, 1995, 23: 921-924

13 Gaillardet J, Dupre B, Allegre C J. Geochemistry of large river suspended sediments: Silicate weathering or recycling tracer. Geochim Cosmochim Acta, 1999, 63: 4037-4051

14 Duzgoren-Aydin N S, Aydin A. Indices for scaling and predicting weathering-induced changes in rock properties. Environ Eng Geosci, 2002, 2: 121-135

15 Price J R, Velbel M A. Chemical weathering indices applied to weathering profiles developed on heterogeneous felsic metamorphic parent rocks. Chem Geol, 2003, 202: 397-416

16 Ohta T, Arai H. Statistical empirical index of chemical weathering in igneous rocks: A new tool for evaluating the degree of weathering. Chem Geol, 2007, 240: 280-297

17 Roddaz M, Viers J, Brusset S, et al. Controls on weathering and provenance in the Amazonian foreland basin: Insights from major and trace element geochemistry of Neogene Amazonian sediments. Chem Geol, 2006, 226: 31-65

18 Vital H, Stattegger K. Major and trace elements of stream sediments from the lowermost Amazon River. Chem Geol, 2000, 168: 151-168

19 Yang S Y, Jung H S, Li C X. Two unique weathering regimes in the Changjiang and Huanghe drainage basins: geochemical evidence from river sediments. Sediment Geol, 2004, 164: 19-34

20 Li C, Yang S Y. Is chemical index of alteration a reliable proxy for chemical weathering in global drainage basins? Am J Sci, 2010, 310 : $111-127$

21 Ahmad T, Khanna P P, Chakrapani G J, et al. Geochemical characteristics of water and sediment of the Indus river, Trans-Himalaya, India: Constraints on weathering and erosion. J Asian Earth Sci, 1998, 16: 333-346

22 Singh M, Sharma M, Tobschall H J. Weathering of the Ganga alluvial plain, northern India: Implications from fluvial geochemistry of the Gomati River. Appl Geochem, 2005, 20: 1-21

23 Tripathi J K, Ghazanfari P, Rajamani V, et al. Geochemistry of sediments of the Ganges alluvial plains: Evidence of large-scale sediment recycling. Quat Int, 2007, 159: 119-130

24 Borges J, Huh Y, Moon S, et al. Provenance and weathering control on river bed sediments of the eastern Tibetan Plateau and the Russian Far East. Chem Geol, 2008, 254: 52-72

25 Liu Z, Zhao Y L, Colin C, et al. Chemical weathering in Luzon, Philippines from clay mineralogy and major-element geochemistry of river sediments. Appl Geochem, 2009, 24: 2195-2205

26 Selvaraj K, Chen T A. Moderate chemical weathering of subtropical Taiwan: Constraints from solid-phase geochemistry of sediments and sedimentary rocks. J Geol, 2006, 114: 101-116

27 乔彦松, 赵志中, 王燕, 等. 川西甘孜黄土-古土壤序列的地球化学演变特征及其古气候意义. 科学通报, 2010, 55: 255-260

28 姚政权, 肖国桥, 梁美艳. 华北平原 BZ_2 钻孔沉积物的常量元素地球化学组成与化学风化. 科学通报, 2009, 54: 3400-3403

29 McLennan S M. Weathering and global denudation. J Geol, 1993, 101: 295-303

30 Yang S Y, Li C X. Elemental composition in the sediments of the Yangtze and the Yellow Rivers and their tracing implication. Prog Nat Sci, 2000, 10: 612-618

31 Kautz C Q, Martin C E. Chemical and physical weathering in New Zealand's Southern Alps monitored by bedload sediment major element composition. Appl Geochem, 2007, 22: 1715-1735

32 Nesbitt H W, Young G M. Prediction of some weathering trends of plutonic and volcanic rocks based on thermodynamic and kinetic considerations. Geochim Cosmochim Acta, 1984, 48: 1523-1534

33 Nesbitt H W, Young G M. Formation and diagenesis of weathering profiles. J Geol, 1989, 97: 129-147

34 陈骏, 王洪涛, 鹿化煜. 陕西洛川黄土沉积物中稀土元素及其它微量元素的化学淋虑研究. 地质学报, 1996, 70: 61-72

35 Song Y H, Choi M S. REE geochemistry of fine-grained sediments from major rivers around the Yellow Sea. Chem Geol, 2009, 266: 328-342

36 Mao C P, Chen J, Yuan X, et al. Seasonal variation the mineralogy of the suspended particulate matter of the lower Changjiang River at Nanjing, China. Clays Clay Miner, 2010, 58: 691-706

37 Viers J, Dupre B, Gaillardet J. Chemical composition of suspended sediments in World River: New insights from a new database. Sci Total Environ, 2008, 407: 853-868

38 Yang S L, Zhao Q Y, Belkin I M. Temporal variation in the sediment load of the Yangtze River and the influences of human activities. J Hydrol, 2002, 263: 56-71

39 王兆印, 黄文典, 李义天。长江流域泥沙输移与概算. 泥沙研究, 2007, 2: 1-10

40 Potter P E, Maynard J B, Depetris P J. Mud and Mudstones. Berlin: Springer, 2005. 157-174

41 Chen Z, Gupta A, Yin H F. Monsoon rivers of Asia. Geomorphology, 2007, 85: 129-130 
42 陈静生. 河流水质原理及中国河流水质. 北京: 科学出版社, 2006. 103-126

43 Chen Z Y, Wang Z H, Finlayson B, et al. Implication of flow control by the Three Gorges Dam on sediment and channel dynamics of the middle Yangtze (Changjiang) river, China. Geol Soc Am, 2010, 38: 1043-1046

44 Johnsson M J, Meade R H. Chemical weathering of fluvial sediments during alluvial storage: The Macupanim Island point bar, Solimoes River, Brazil. J Sediment Petrol, 1990, 60: 827-842

45 Derry L A, France-Lanord C. Neogene Himalayan weathering history and river ${ }^{87} \mathrm{Sr} /{ }^{86} \mathrm{Sr}$ : Impact on the marine Sr record. Earth Planet Sci Lett, 1996, 142: 59-76

46 Heller P L, Peter E B, Humphrey N F, et al. Paradox of downstream fining and weathering-rind formation in the lower Hoh River, Olympic Peninsula, Washington. Geology, 29: 971-974

47 茅昌平. 长江流域沉积物(悬浮物)的地球化学和矿物学研究. 博士学位论文. 南京: 南京大学, 2009

48 唐晶晶. 1952 2007 年间长江流域降水时空分布变化-全球变暖下降水重新分配实例分析. 硕士学位论文. 上海: 华东师范大学, 2010

49 戴仕宝, 杨世伦, 赵华云, 等. 三峡水库蓄水运用初期长江中下游河道冲淤响应. 泥沙研究, 2005, 5: 35-39

50 Xu B K, Milliman J D, Yang Z, et al. Yangtze sediment decline partly from Three Gorges Dam. EOS Trans AGU, 2006, 87: 185-196

51 Yang Z, Wang H, Saito Y, et al. Dam impacts on the Changjiang (Yangtze) River sediment discharge to the sea: The past 55 years and after the Three Gorges Dam. Water Resour Res, 2006, 42: 1-10

- 动 态

\section{有害重金属镍的大气排放污染研究取得新进展}

重金属污染是当今环境领域的热点问题. 大气排放是 重金属污染环境及危害人类健康的主要途径之一, 已逐渐 成为科学家研究和公众高度关注的前沿. 近年来, 中国大 气有害重金属排放及污染特征方面的研究也取得了实质性 进展, 先后建立了如 $\mathrm{Hg}, \mathrm{As}, \mathrm{Pb}, \mathrm{Cr}$ 等有害元素的人为源大 气排放清单。镍及镍化合物被美国、日本等许多政府及国 际组织认定为如同 $\mathrm{Hg}, \mathrm{Pb}, \mathrm{Cr}$ 等危害人类健康和污染环境 的有毒有害重金属之一, 国际癌症研究机构(IARC)将其列 为潜在的致癌物质. 欧美等发达国家和地区已经相继建立 了各自的大气镍排放清单. 然而之前国内鲜有关于重金属 镍的大气排放及污染特征研究的报道. 在重金属污染事故 凸显的今天, 开展重金属镍的大气排放及污染特征的研究, 建立详细的人为活动大气镍排放清单, 不仅推进了重金属 大气排放及污染特征方面的研究, 还可为国家开展有害重 金属污染综合防治提供科学依据和数据基础.

由北京师范大学环境学院环境模拟与污染控制国家重 点实验室的田贺忠教授研究小组撰写的“Anthropogenic atmospheric nickel emissions and its distribution characteristics in China”一文初步回答了这个问题, 该文发表在 Science of The Total Environment 2012 年第 417-418 期上. 田贺忠及 其合作者比较系统地建立了 1980 2009 年中国由人为活动 导致的大气有害重金属镍的排放清单.
研究表明, 近 30 年来中国大陆地区重金属镍的大气排 放总量呈逐渐上升趋势, 其中主要来源于燃料的燃烧过程. 2009 年全国大气镍排放近 4000 吨, 燃料燃烧贡献超过了 $80 \%$, 其中煤炭燃烧占据主要部分. 随着中国经济的快速 发展、国家能源结构和产业结构的调整, 工业生产活动排 放的大气镍所占比重正逐渐增大, 垃圾焚烧预计也将成为 今后重金属镍大气排放的重要人为源之一. 全国范围来看, 排放强度最大的地区主要集中在京津冀、珠江三角洲及长 江三角洲等经济发达及人口稠密地区. 2000 年以来, 中国 大气镍排放的年均增长率约为 $6 \%$, 应该引起全社会的高 度关注和重视。

该研究的创新之处在于通过对包括燃煤源和非燃煤源 的中国各种人为源的活动水平和大气有害重金属镍排放状 况的综合分析研究, 比较详细地报道了 1980 2009 年中国 大陆地区各种人为活动导致的有害重金属镍的大气排放清 单及其时空分布特征. 该研究有助于科学家、政府决策者 及公众深人了解中国的有害重金属镍的大气排放污染历 史、现状及发展趋势，可为国家和地方政府制定相关法规、 标准及政策, 开展有害重金属污染综合防治提供科学依据, 该研究得到了国家自然科学基金 (20677005, 40975061, 21177012)和北京市自然科学基金(8113032)资助.

(本刊讯) 